\title{
Studi Petrografi Batuan Beku dan Sinter Silika di Kecamatan Alam Pauh Duo, Kabupaten Solok Selatan
}

\author{
Sauri Aulia Putri ${ }^{1, *}$, Ardian Putra ${ }^{1}$, Mirzam Abdurrachman ${ }^{2}$ \\ ${ }^{1}$ Laboratorium Fisika Bumi, Jurusan Fisika \\ Fakultas Matematika dan Ilmu Pengetahuan Alam, Universitas Andalas \\ Kampus UNAND Limau Manis, Padang, 25163, Indonesia \\ ${ }^{2}$ Laboratorium Petrologi, Jurusan Teknik Geologi \\ Fakultas Ilmu dan Teknologi Kebumian, Institut Teknologi Bandung \\ Jl. Ganesha, Coblong, Kota Bandung, 40132, Indonesia \\ *auliasauri@gmail.com
}

\begin{abstract}
ABSTRAK
Telah dilakukan analisis petrografi terhadap batuan beku dan sinter silika di Kecamatan Alam Pauh Duo, Kabupaten Solok Selatan. Penelitian ini bertujuan untuk mengetahui kenampakan mikroskopik batuan meliputi struktur dan tekstur, komposisi mineral penyusun batuan, jenis, dan nama batuan. Batuan diambil pada empat titik di Kecamatan Alam Pauh Duo, sedangkan sinter silika diambil di sekitar mata air panas Sapan Maluluang. Batuan dan sinter silika dipreparasi menjadi sayatan tipis. Analisis dilakukan menggunakan mikroskop polarisasi dan X-Ray Diffractometer (XRD). Hasil analisis menunjukkan bahwa batuan pada Kecamatan Alam Pauh Duo didominasi oleh batuan beku basalt. Batuan ini menunjukkan struktur masa batuan yang seragam. Batuan beku basalt ini disusun oleh mineral primer dan sekunder. Mineral primer berupa plagioklas, piroksen, dan hornblen. Mineral sekunder berupa klorit, kalsit, dan kuarsa. Mineral sekunder ini mengindikasikan bahwa temperatur reservoir panas bumi di Kecamatan Alam Pauh Duo berkisar antara $120^{\circ} \mathrm{C}-320^{\circ} \mathrm{C}$. Nilai estimasi ini berada dalam kisaran nilai estimasi temperatur reservoir yang diperoleh oleh PT. Supreme Energy yaitu $210^{\circ} \mathrm{C}-320^{\circ} \mathrm{C}$.
\end{abstract}

Kata kunci: batuan beku basalt, petrografi, temperatur reservoir

\section{ABSTRACT}

Petrography's observation to thin section of rock and silica sinter has been done at Kecamatan Alam Pauh Duo, Kabupaten Solok Selatan. Petrography analysis was used for identifying the structure, texture, and mineral content of rock. The rock was taken at four points in Kecamatan Alam Pauh Duo, and silica sinter was taken around Sapan Maluluang's hot spring. The rock and silica sinter was prepared to be thin section. The observation was done by using polarization microscope and X-Ray Diffractometer (XRD). The result shows that the rock at Kecamatan Alam Pauh Duo is dominated by basalt rock. This rock shows the uniform structure of rock mass. This rock was arranged by primary and secondary mineral. Primary mineral are plagioclase, pyroxene, and homblend. Secondary mineral are chlorite, calcite, and quartz. The secondary mineral indicates that temperature of geothermal reservoir at Kecamatan Alam Pauh Duo is ranges from $120^{\circ} \mathrm{C}$ to $320^{\circ} \mathrm{C}$. This temperature is in the range of PT. Supreme Energy's estimated value.

Keywords: basalt rock, petrography, reservoir temperature

\section{PENDAHULUAN}

Kabupaten Solok Selatan berada pada sistem Patahan Semangko dan jalur gunung berapi yang masih aktif. Patahan Semangko merupakan patahan yang muncul akibat interaksi oblik antara Lempeng Eurasia dan Indo-Australia. Patahan ini masih aktif dengan laju pergerakan $7 \mathrm{~cm} /$ tahun. Gunung berapi aktif yang mempengaruhi tatanan geologi Kabupaten Solok Selatan adalah Gunung Kerinci di Kabupaten Kerinci. Posisi geologi ini menyebabkan adanya potensi sumber daya mineral dan energi. Sumber daya tersebut antara lain mineral logam (tembaga, emas, dan perak), bahan galian (batu gamping, pasir, dan batu sungai), dan potensi energi panas bumi (Pemerintah Kabupaten Solok Selatan, 2017).

Potensi energi panas bumi di Kabupaten Solok Selatan ditandai dengan munculnya manifestasi panas bumi berupa mata air panas dan endapan mineral. Endapan tersebut berasal dari mineral-mineral yang dibawa oleh fluida lalu mengendap saat di permukaan bumi. Bentuk dari endapan tersebut yaitu sinter silika dan sinter karbonat. Pembentukan endapan sinter dikontrol oleh konsentrasi mineral yang berada di reservoir panas bumi. Sinter termasuk ke dalam batuan sedimen (Harris dan King., 1986). 
Pengamatan mikroskopik batuan akan memberikan informasi untuk melengkapi data awal ekplorasi panas bumi. Pengamatan mikroskopik batuan dapat dilakukan menggunakan metode petrografi sayatan tipis. Metode petrografi sayatan tipis digunakan oleh Indarto dkk. (2006) untuk mempelajari batuan pada lapangan panas bumi Gedongsongo di Jawa Tengah. Batuan yang diamati berada di sekitar manifestasi panas bumi. Manifestasi panas bumi yang terdapat pada lapangan panas bumi Gedongsongo berupa fumarola dan mata air panas. Metode petrografi sayatan tipis digunakan untuk mengetahui struktur, tekstur, dan kandungan mineral batuan. Studi ini juga menggunakan difraksi sinar-X untuk mengetahui mineral ubahan dan jenis mineral lempung di dalam contoh batuan. Hasil dari studi tersebut yaitu batuan ubahan yang terbentuk ditunjukkan oleh munculnya mineral-mineral haloisit, kaolinit, silika amorf, kristobalit, ilit, malkasit, dan pirit. Mineral-mineral ini dapat mengindikasikan suhu batuan reservoir bawah permukaan lapangan panas bumi Gedongsongo sekitar $70^{\circ} \mathrm{C}$ sampai $200^{\circ} \mathrm{C}$.

Metode petrografi sayatan tipis juga digunakan oleh beberapa peneliti yaitu Reyes (1990), Khalifa, dkk. (2011), dan Kulahci, dkk. (2017) untuk mengetahui suhu bawah permukaan pada lapangan geotermal. Hasil dari analisis petrografi terhadap batuan sampel adalah ditemukannya mineral-mineral hidrotermal. Mineral hidrotermal tersebut adalah ilit, biotit, epidot, dan kaolinit. Mineral-mineral ini mengindikasikan temperatur bawah permukaan berkisar antara $120^{\circ} \mathrm{C}$ sampai dengan $340^{\circ} \mathrm{C}$.

Studi petrografi sayatan tipis batuan perlu dilakukan untuk memahami vulkanisme dan struktur geologi daerah prospek panas bumi. Pemahaman tentang vulkanisme dan struktur geologi sangat diperlukan untuk eksplorasi awal daerah prospek panas bumi. Maka dari itu penelitian ini perlu dilakukan untuk menganalisis petrografi sayatan tipis singkapan batuan di Kabupaten Solok Selatan. Analisis petrografi sayatan tipis batuan akan memberikan informasi tentang kenampakan mikroskopis batuan. Kenampakan mikroskopis tersebut meliputi struktur batuan/ mineralisasi, komposisi mineral penyusun batuan, jenis batuan, dan nama batuan (Umar dkk., 2014). Penelitian ini juga menggunakan X-Ray Diffractometer (XRD) untuk menentukan mineral-mineral hidrotermal atau mineral-mineral lempung yang mungkin terdapat pada batuan sampel. Hasil dari penelitian ini diharapkan bisa digunakan untuk mengetahui potensi sistem panas bumi di Kabupaten Solok Selatan.

\section{METODE}

Penelitian ini dilakukan di Laboratorium Fisika Bumi Jurusan Fisika Universitas Andalas, Laboratorium Petrologi Jurusan Geologi Institut Teknologi Bandung, dan Laboratorium Fisika Universitas Negeri Padang. Penelitian dilakukan dari April sampai Agustus 2018. Lokasi yang menjadi objek penelitian adalah Kecamatan Alam Pauh Duo, Kabupaten Solok Selatan.

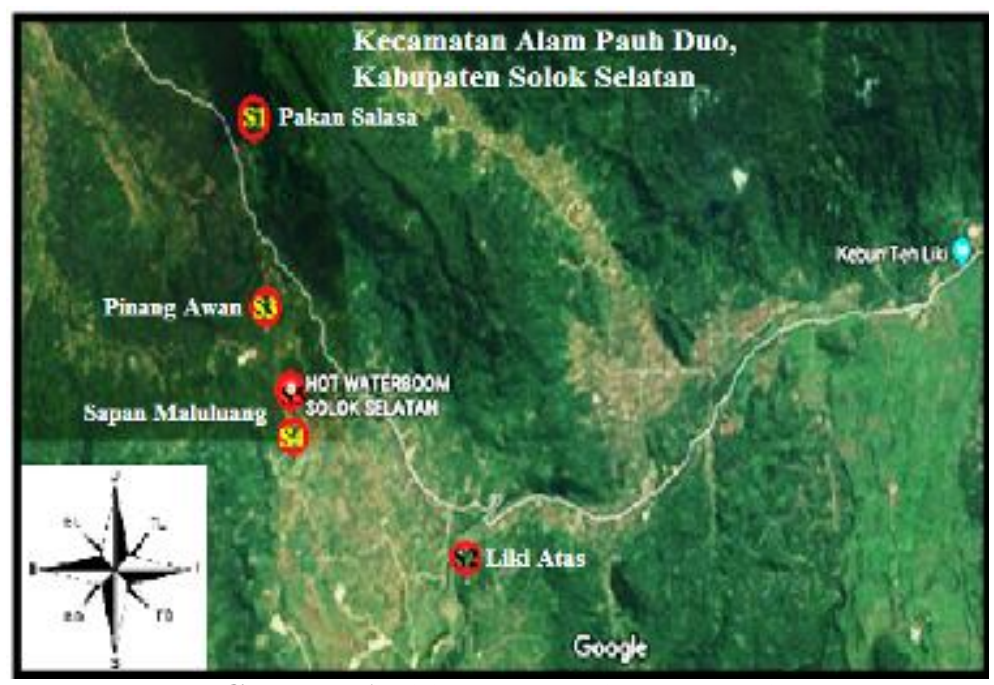

Gambar 1 Titik Pengambilan Sampel 
Sampel yang diambil adalah batuan beku dan sinter silika. Batuan beku diambil berdasarkan peta geologi daerah tersebut. Batuan beku diambil pada 4 titik (Gambar 1). Sinter silika diambil pada 1 titik di dekat sumber mata air panas Sapan Maluluang (Gambar 1). Sampel dipreparasi menjadi sayatan tipis dan bubuk. Sayatan tipis batuan diamati menggunakan mikroskop polarisasi. Bubuk batuan dikarakterisasi menggunakan X-Ray Diffractometer.

\section{HASIL DAN DISKUSI}

\subsection{Petrologi Sampel 1}

Secara makroskopik (Gambar 2b), batuan ini berwarna abu-abu terang. Mineral pada batuan dapat dibedakan secara kasat mata (fanerik), dan terdiri dari fenokris dan massa dasar. Fenokris terdiri dari kuarsa (2\%), plagioklas (4\%), dan piroksen $(3 \%)$ yang tertanam dalam massa dasar (91\%). Massa dasar terdiri atas mineral mafik, yaitu mineral berwarna gelap. Secara mikroskopik (Gambar 2a), terlihat bahwa jenis kristalinitas batuan ini adalah hipokristalin. Hubungan antar kristal adalah inequigranular. Tekstur kristal adalah intergranular, tetapi pada beberapa tempat menunjukkan intersertal. Fenokris $(28 \%)$ terdiri dari plagioklas, piroksen, dan mineral opak. Massa dasar (72\%) terdiri atas gelas, piroksen, plagioklas, dan mineral opak.

Plagioklas (55\%) terdapat sebagai fenokris dan massa dasar. Plagioklas sebagai fenokris (20\%) terlihat segar, yaitu bentuk kristalnya masih jelas. Jenis kembarannya carlsbad, carlsbad-albit, dan albit. Plagioklas berukuran 0,125 mm-2,375 mm dengan bentuk kristal mineral yaitu subhedral-anhedral. Pada sebagian plagioklas terdapat zonasi dan sebagian menunjukan adanya bercak-bercak (coarse-sieving). Jenis plagioklas adalah bytownite-anorthite $\left(\mathrm{An}_{86-92}\right)$, dan setempat terinklusi mineral opak. Sebagai massa dasar (35\%) kehadiran plagioklas melimpah, bentuknya prismatik, tersebar bersama piroksen, mineral opak, dan gelas.
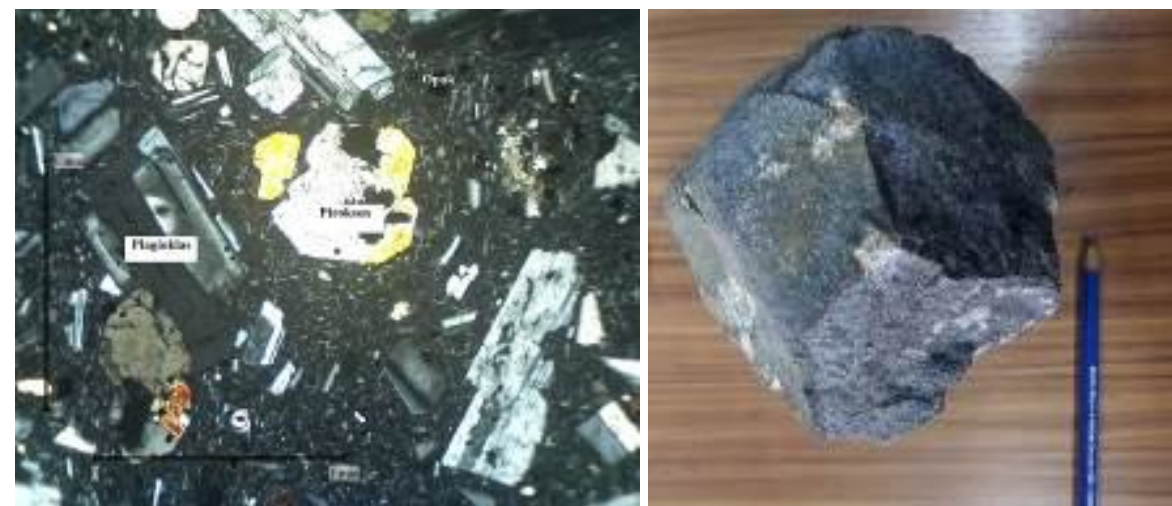

Gambar 2 (a) Fotomikrografi Sampel 1 (XPL) dan (b) Makroskopik sampel 1

Piroksen (10\%) terdapat sebagai fenokris dan massa dasar. Sebagai fenokris (4\%), terlihat segar, yaitu bentuk kristalnya masih jelas. Piroksen berukuran $0,1 \mathrm{~mm}-3,5 \mathrm{~mm}$ dengan bentuk kristal mineral subhedral-anhedral. Sebagian kembarannya menunjukan kembaran polisintetik. Mineral piroksen terinklusi mineral opak pada beberapa tempat. Sebagai massa dasar (6\%), bentuknya prismatik, tersebar merata bersama plagioklas dan gelas. Piroksen terbagi menjadi orto-piroksen (3\%) dan klino-piroksen (7\%).

Mineral Opak (5\%) tersebar sebagai fenokris dan massa dasar. Sebagai fenokris (4\%) berukuran ukuran 0,1 mm-0,6 mm. Mineral opak berbentuk anhedral. Sebagai massa dasar (1\%), hadir merata bersama gelas, piroksen, dan plagioklas. Selanjutnya, gelas (30\%) sebagai massa dasar (30\%) hadir melimpah bersama plagioklas, piroksen, dan mineral opak.

\subsection{Petrologi Sampel 2}

Pada Gambar 3b dapat dilihat hasil pengamatan makroskopik, batuan ini berwarna abuabu gelap. Mineral dapat dibedakan secara kasat mata (fanerik). Batuan memiliki ukuran butir yang tidak seragam (porfiritik). Batuan terdiri dari fenokris dan massa dasar. Fenokris terdiri dari kuarsa $(2 \%)$, piroksen $(5 \%)$, dan plagioklas (10\%). Fenokris tertanam dalam massa dasar 
(83\%) yang terdiri atas mineral mafik. Secara mikroskopik (Gambar 3a), sampel 2 merupakan sayatan tipis basalt, hipokristalin, inequigranular, intergranular, dan setempat menunjukan intersertal. Fenokris (32\%) terdiri dari plagioklas, piroksen, klorit, dan mineral opak. Massa dasar (68\%) terdiri atas gelas, piroksen, plagioklas, dan mineral opak (Gambar 3).
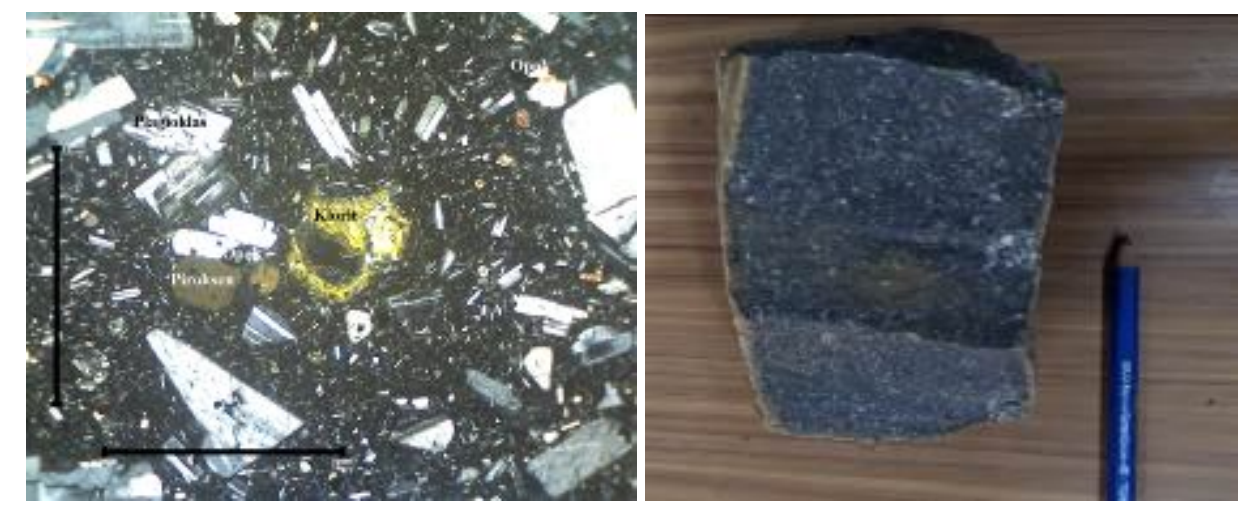

Gambar 3 (a) Fotomikrografi Sampel 2 (XPL) dan (b) Makroskopik sampel 2

Plagioklas (55\%) terdapat sebagai fenokris dan massa dasar. Sebagai fenokris (25\%), plagioklas memiliki kembaran carlsbad dan carlsbad-albit. Plagioklas berukuran 0,075 mm2,75 mm, berbentuk subhedral-anhedral. Sebagian plagioklas terdapat zonasi dan sebagian menunjukan coarse-sieving. Komposisi plagioklas berupa bytownite-anorthite $\left(\mathrm{An}_{85-92}\right)$. Pada beberapa tempat, plagioklas terinklusi oleh mineral opak. Sebagai massa dasar (30\%), kehadiran plagioklas melimpah, memiliki bentuk prismatik, dan tersebar merata bersama piroksen, mineral opak, dan gelas.

Piroksen $(6 \%)$ terdapat sebagai fenokris dan massa dasar. Sebagai fenokris (4\%), berukuran $0,125 \mathrm{~mm}-1,125 \mathrm{~mm}$, subhedral-anhedral, sebagian kembarannya menunjukan kembaran polisintetik, dan setempat terinklusi mineral opak. Sebagai massa dasar (2\%), bentuknya prismatik, tersebar merata bersama plagioklas dan gelas. Piroksen terbagi menjadi orto-piroksen (1\%) dan klino-piroksen (5\%).

Mineral opak (4\%) juga terdapat sebagai fenokris dan massa dasar. Sebagai fenokris (3\%), berukuran 0,05 mm- $0,425 \mathrm{~mm}$, anhedral. Sebagai massa dasar (1\%), hadir bersama gelas, plagioklas, dan piroksen. Kemudian gelas (34\%) hadir sebagai massa dasar (34\%) bersama plagioklas, piroksen, dan mineral opak. Klorit (1\%) ditemukan sebagai mineral sekunder. Berwarna hijau dengan bentuk anhedral.

\subsection{Petrologi Sampel 3}

Hasil pengamatan secara makroskopik (Gambar 4b), terlihat bahwa batuan ini berwarna abu-abu gelap, fanerik, dan porfritik. Fenokris terdiri dari kuarsa (3\%), plagioklas (20\%), dan piroksen (10\%). Fenokris tertanam dalam massa dasar $(67 \%)$ yang terdiri atas mineral mafik. Secara mikroskopik (Gambar 4a), sampel 3 merupakan sayatan tipis basalt dengan jenis kristalinitas adalah hipokristalin, inequigranular, intergranular. Fenokris $(25 \%)$ terdiri dari plagioklas, piroksen, dan mineral opak yang tertanam dalam massa dasar (75\%). Massa dasar terdiri atas gelas, piroksen, plagioklas, dan mineral opak.

Plagioklas (40\%) terdapat sebagai fenokris dan massa dasar. Sebagai fenokris (19\%) berukuran 0,125 mm-4 mm. Jenis kembarannya carlsbad dan carlsbad-albit. Bentuknya subhedral-anhedral. Zonasi dan coarse-sieving terdapat pada beberapa tempat. Komposisi dari plagioklas yaitu bytownite $\left(\mathrm{An}_{85}\right)$. Plagioklas terinklusi mineral opak pada beberapa tempat. Sebagai massa dasar $(21 \%)$ bentuknya prismatik.

Piroksen $(5 \%)$ terdapat sebagai fenokris dan massa dasar. Piroksen terbagi menjadi orto-piroksen (4\%) dan klino-piroksen (1\%). Sebagai fenokris (3\%), segar, berukuran 0,1 mm3,5 mm, subhedral-anhedral, sebagian kembarannya menunjukan kembaran polisintetik, dan setempat terinklusi mineral opak. Sebagai massa dasar (2\%), bentuknya prismatik, tersebar merata bersama plagioklas, mineral opak, dan gelas. 
Mineral Opak (4\%) hadir sebagai fenokris dan massa dasar. Sebagai fenokris (3\%), ukuran $0,075 \mathrm{~mm}-1,45 \mathrm{~mm}$, anhedral. Sebagai massa dasar (1\%), hadir bersama gelas, plagioklas, dan piroksen. Selanjutnya, gelas $(51 \%)$ sebagai massa dasar (51\%) hadir melimpah bersama plagioklas, piroksen, dan mineral opak.
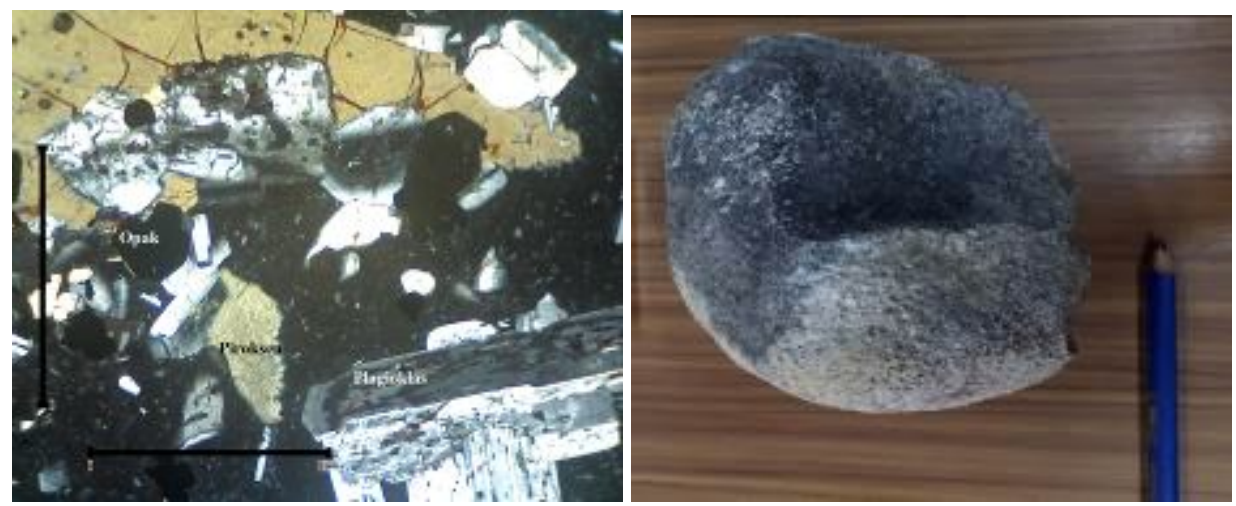

Gambar 4 (a) Fotomikrografi Sampel 3 (XPL) dan (b) Makroskopik sampel 3

\subsection{Petrologi Sampel 4}

Berdasarkan pengamatan makroskopik (Gambar 5b), batuan berwarna abu-abu gelap, fanerik, dan porfiritik. Fenokris terdiri dari kuarsa (2\%), plagioklas (5\%), dan piroksen (10\%). Fenokris tertanam dalam massa dasar $(83 \%$ yang terdiri dari mineral mafik. Permukaan luar sebagian terubah dengan keterdapatan mineral silika. Secara mikroskopik (Gambar 5a), jenis kristalinitasnya adalah hipokristalin. Hubungan antar terkstur adalah inequigranular. Teksturnya intergranular, tetapi setempat menunjukan intersertal. Fenokris $(30 \%)$ terdiri dari plagioklas, piroksen, hornblenda, dan mineral opak. Massa dasar (70\%) terdiri atas gelas, piroksen, plagioklas, dan mineral opak.

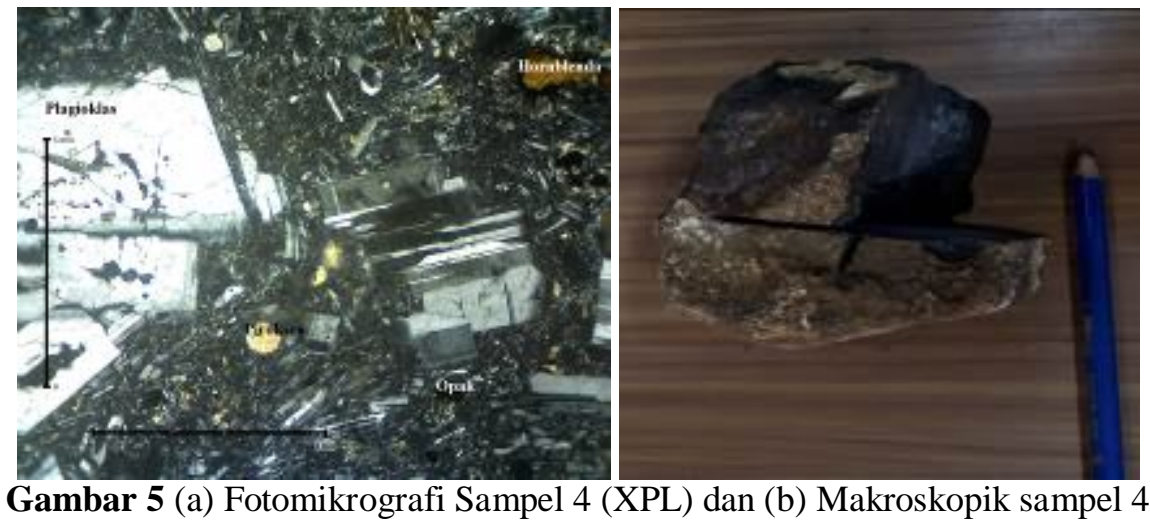

Plagioklas (50\%) hadir sebagai fenokris dan massa dasar. Sebagai fenokris (20\%), segar, kembarannya carlsbad, carlsbad-albit, dan berukuran $0,1 \mathrm{~mm}-4,25 \mathrm{~mm}$. Bentuknya subhedral-anhedral. Ditemukan zonasi dan coarse-sieving pada beberapa tempat. Komposisinya bytownite $\left(\mathrm{An}_{88-90}\right)$. Plagioklas terinklusi mineral opak pada beberapa tempat. Sebagai massa dasar $(30 \%)$, melimpah, bentuknya prismatik.

Piroksen (5\%) hadir sebagai fenokris dan massa dasar. Sebagai fenokris (3\%), piroksen berukuran $0,1 \mathrm{~mm}-1 \mathrm{~mm}$. Bentuknya subhedral-anhedral. Terdapat kembaran polisintetik yang terinklusi mineral opak pada beberapa tempat. Sebagai massa dasar (2\%), bentuknya prismatik, tersebar merata bersama plagioklas dan gelas. Piroksen terbagi menjadi orto-piroksen (1\%), klino-piroksen $(4 \%)$.

Hornblenda (4\%) hadir sebagai fenokris (4\%) dengan ukuran 0,375 $\mathrm{mm}-0,5 \mathrm{~mm}$, anhedral, dan dikelilingi mineral opak. Mineral Opak (4\%) sebagai fenokris (3\%), ukuran $0,0125 \mathrm{~mm}-0,5 \mathrm{~mm}$, anhedral. Sebagai massa dasar (1\%), hadir bersama gelas dan plagioklas. Gelas (37\%) sebagai massa dasar (37\%) hadir melimpah bersama plagioklas dan mineral opak. 


\subsection{Petrologi Sampel 5}

Sayatan tipis sinter (Gambar 6a), tekstur non-klastik, terpilah buruk, kemas terbuka, kebundaran subangular-subrounded. Butiran berukuran 0,1 $\mathrm{mm}-0,75 \mathrm{~mm}$, terdiri dari dolomit, kuarsa, dan mineral oksida. Matriks berupa mikrit. Semen berupa mineral oksida. Dolomit berukuran $0,1 \mathrm{~mm}-0,75 \mathrm{~mm}$, subrounded. Kuarsa berukuran $0,025 \mathrm{~mm}-0,04 \mathrm{~mm}$, subangularsubrounded. Mineral oksida sebagai semen. Mineral karbonat sebagai matriks.
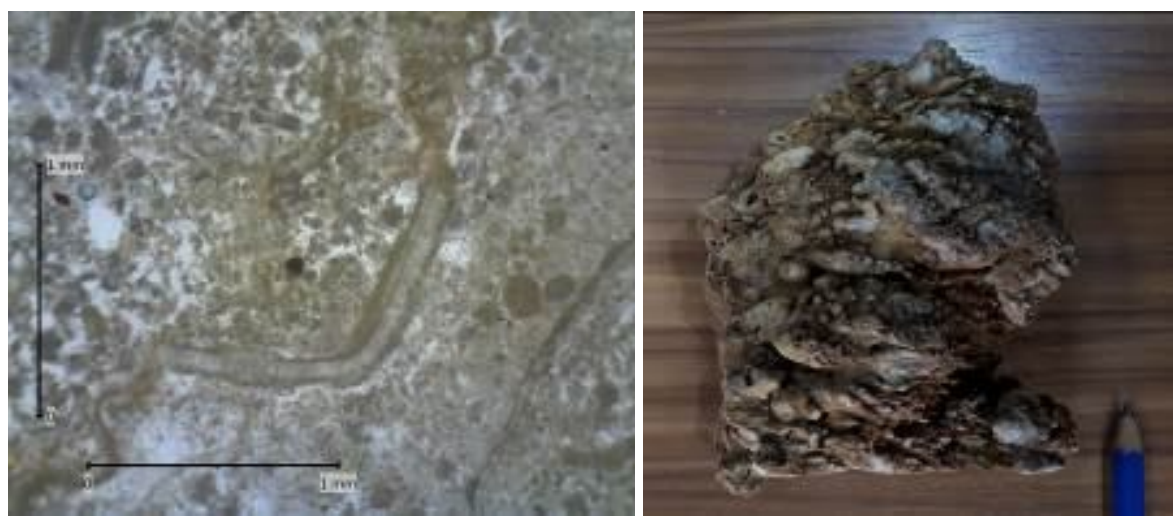

Gambar 6 (a) Fotomikrografi Sampel 5 (XPL) dan (b) Makroskopik sampel 5

\subsection{Jenis Batuan dan Estimasi Temperatur Bawah Permukaan}

Hasil pengamatan mikroskopik menunjukkan bahwa batuan sampel 1, 2, 3, dan 4 adalah batuan beku basalt, sedangkan sampel 5 merupakan endapan mineral yang didominasi oleh silika amorf, dan sebagian ditemukan mineral kalsit dan dolomit. Batuan beku basalt merupakan batuan vulkanik, artinya batuan tersebut terbentuk saat proses vulkanik yang mengeluarkan lava yang kemudian membeku karena terkena kontak dengan udara. Batuan ini adalah batuan ekstrusi, yaitu batuan yang pembekuannya terjadi di permukaan bumi. Batuan ini didominasi oleh mineral plagioklas dan piroksen, sehingga batuan ini masuk ke dalam batuan beku basa.

Hasil pengamatan mikroskopik terhadap sampel 1, 2, 3, dan 4 menunjukkan struktur batuan berupa fenokris dan massa dasar. Fenokris memiliki ukuran yang berbeda, mulai dari yang berukuran terbesar sampai terkecil. Ukuran fenokris lebih besar dari pada massa dasar, ini menandakan fenokris terbentuk lebih dahulu dari massa dasar. Ukuran fenokris yang beragam ini artinya mineral terbentuk secara bertahap pada temperatur dan tekanannya masing-masing. Ketika batuan beku membeku pada temperatur dan tekanan tinggi di bawah permukaan dengan waktu yang relatif lama, maka mineral-mineral penyusunnya memiliki waktu untuk membentuk sistem kristal tertentu dengan ukuran mineral relatif besar. Kondisi pembekuan dengan temperatur dan tekanan yang rendah, mineral-mineral penyusun batuan beku tidak sempat membentuk sistem kristal tertentu, sehingga terbentuklah gelas yang tidak memiliki sistem kristal. Mineral yang terbentuk biasanya berukuran relatif kecil.

Analisis petrografi di bawah mikroskop polarisasi menunjukan bahwa sampel 1, 2, 3, dan 4 merupakan batuan beku basalt. Jenis batuan sama, tetapi terdapat perbedaan pada ukuran mineral, bentuk mineral, persentase mineral primer, dan mineral sekunder penyusun batuan tersebut. Mineral sekunder terdapat pada pada sampel batuan ke 2 dan ke 4 . Pada sampel 2 ditemukan mineral sekunder berupa klorit, sedangkan pada sampel 4 ditemukan mineral kuarsa. Mineral sekunder ini dapat mengindikasikan temperatur bawah permukaan lapangan panas bumi adalah $220^{\circ} \mathrm{C}$ sampai dengan $320^{\circ} \mathrm{C}$ (Morrison, 1995). Berdasarkan persentase mineral sekunder ini, dapat diketahui bahwa batuan hanya terubah dengan intensitas rendah, sehingga dapat dikatakan sebagai batuan segar.

Hasil analisis menggunakan XRD pada sampel 4 (Gambar 7) menunjukkan adanya mineral hidrotermal berupa kristobalit. Hasil XRD sampel 5 (Gambar 8) menunjukkan adanya mineral hidrotermal berupa kalsit dan kuarsa. Mineral-mineral hidrotermal ini dapat mengindikasikan temperatur bawah permukaan daerah prospek panas bumi. Kalsit dan kuarsa mengindikasikan temperatur bawah permukaan berkisar dari $100^{\circ} \mathrm{C}-360^{\circ} \mathrm{C}$ (Morrison, 1995). 


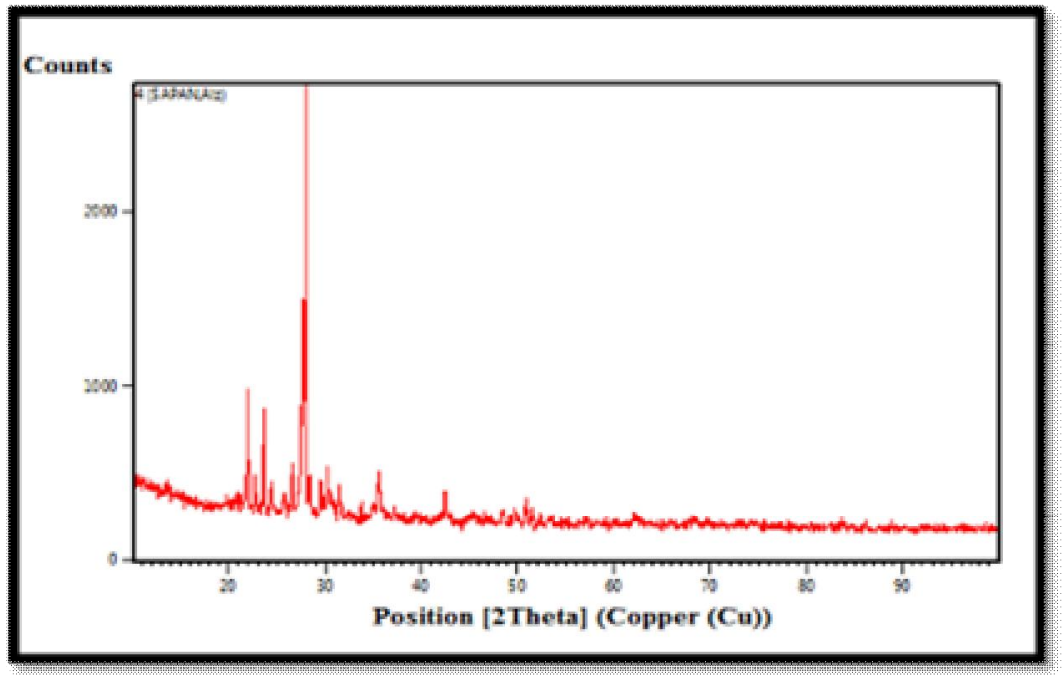

Gambar 7 Pola XRD Sampel 4

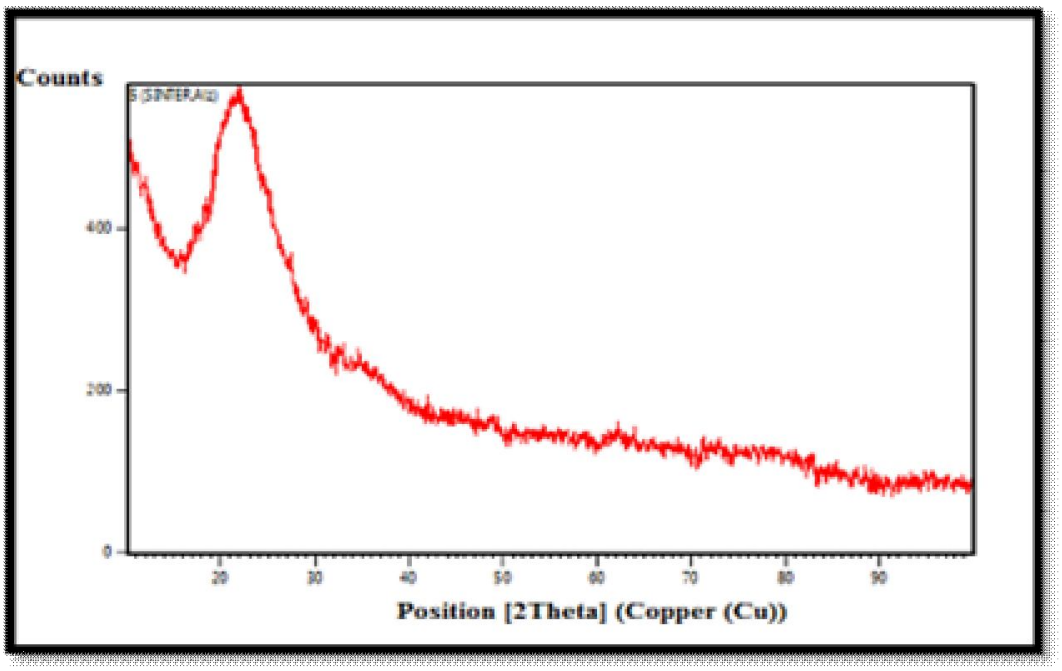

Gambar 8 Pola XRD Sampel 5

Berdasarkan mineral sekunder yang terdapat pada sampel 2, 4, dan 5, maka diperoleh temperatur bawah permukaan daerah penelitian adalah $120^{\circ} \mathrm{C}-320^{\circ} \mathrm{C}$. Estimasi temperatur ini mengindikasikan bahwa daerah ini memiliki potensi panas bumi yang baik dengan reservoir bertemperatur tinggi. Berdasarkan data yang diperoleh pada penelitian ini, dapat diketahui bahwa sistem panas bumi di Kecamatan Alam Pauh Duo, Kabupaten Solok Selatan merupakan sistem panas bumi yang dipengaruhi oleh aktivitas vulkanomagmatik. Gunung api aktif yang mempengaruhi sistem panas bumi pada daerah ini adalah Gunung Kerinci yang berada pada perbatasan Kabupaten Solok Selatan dengan Provinsi Jambi. Aktivitas gunung api ini tidak lepas dari kontrol sistem sesar. Sistem sesar yang mengontrol aktivitas Gunung Kerinci adalah Sesar Sumatera. Berdasarkan manifestasi yang muncul dan tatanan geologinya, daerah ini memiliki potensi panas bumi yang baik untuk terus dikembangkan.

\section{KESIMPULAN}

Berdasarkan analisis petrografi dan analisis menggunakan XRD terhadap 4 sampel batuan dan 1 sampel sinter silika di Kecamatan Alam Pauh Duo, dapat disimpulkan bahwa diperoleh mineral sekunder berupa klorit, kalsit, dan kuarsa pada batuan sampel 2, 4, dan 5 . Mineral sekunder ini memperlihatkan adanya sistem panas bumi pada daaerah pengambilan sampel 2, 4, dan 5. Mineral sekunder yang ditemukan pada batuan sampel mengindikasikan temperatur sistem panas bumi pada daerah tersebut adalah $120^{\circ} \mathrm{C}-320^{\circ} \mathrm{C}$. 


\section{DAFTAR PUSTAKA}

Harris, R.E. dan King, J.K., 1986, Sinter (Including Travertine) Resource of Wyoming, Open File Report, The Geological Survey of Wyoming, State Geologist, Wyoming.

Hochstein, M.P. dan Browne, P.R.L., 2000, Surface Manifestation of Geothermal Systems with Volcanic Heat Sources, In Encyclopedia of Volcanoes, Academic Press.

Indarto, S., Widarto, D.S., Zulkarnain, E.G., Setiawan, I., 2006, Studi Batuan Volkanik dan Batuan Ubahan pada Lapangan Panas Bumi Gedongsongo Kompleks Gunung Api Ungaran Jawa Tengah, Riset Geologi dan Pertambangan, Jilid 16, No. 1, hal 30-34.

Khalifa, I.H., El-Bialy, M.Z., Hassan, D.M., 2011, Petrologic and Geochemical Characterization of the Metavolcanic Rocks of the Heib Formation, Kid Metamorphic Complex, Sinai, Egypt, Geoscience Frontiers, Vol 2, No 3, hal 385-402.

Kulahci, G.D.D., Temel, A., Gourgaud, A., 2017, Mineralogical and Petrological Features of the Cemilköy Ignimbrite, Cappadocia, Turkey, Chemie De Erde.

Morrison, K., 1995, Important Hydrothermal Minerals and Their Significance, Geothermal and Minerals Service Division Limited, Edisi keenam.

Noor, D., 2012, Pengantar Geologi, Pakuan University Press, Bogor.

Reyes, A.G., 1990, Petrology of Philippine Geothermal System and the Application of Alteration Mineralogy to their Assesment, Journal of Volcanology and Geothermal Research, No 43, hal 279-309.

Rosidi, dkk., 1996, Peta Geologi Lembar Painan dan Bagian Timur Laut Lembar Muara Siberut, Sumatera, Padang, Dinas Pertambangan dan Mineral Sumatera Barat.

Pemerintah Kabupaten Solok Selatan, 2017, Letak Geografis dan Topografi, solselkab.go.id/post/read/154/letakgeografis- dan-topografi.html. diakses 1 Februari 2018. 